\title{
Confidence and loose opportunism in the science classroom: towards a pedagogy of investigative science for beginning teachers
}

\author{
Jim McNally (j.g.mcnally@stir.ac.uk)
}

\author{
Institute of Education, University of Stirling, Stirling, Scotland
}

This paper attempts to establish a conceptual basis on which beginning teachers may be introduced to investigative science teaching in a way that accommodates the teacher voice. It draws mainly on preliminary theory from the shared reflections of twenty science teachers, augmented by a more general interview-based study of the experience of early professional learning of eighteen new teachers. Internationally, it is situated in the wider concern in the literature with the nature of science, mainly in initial teacher education. Empirically located within the Scottish context, a grounded epistemological base of teacher knowledge is illustrated and presented as components of confidence in a cycle of professional learning that needs to be set in motion during ITE. It is proposed that, given protected experience in their early attempts to teach investigatively, new teachers can begin to develop a confident pedagogy of loose opportunism that comes close to authentic science for the children they teach.

\section{General background}

The case for more practical investigative science in the classroom is well established. Woolnough (1991), for example, has argued that investigative science ought to be at the very heart of science teaching: Shapiro (1996) has claimed that not to have experienced 'science as investigation' is to miss involvement in understanding the very nature of science. It meets the need to do science as well as learn science and learn about science, to use Hodson's (1993) distinction. Moreover, if this need is to be met by something approaching authentic scientific activity, then the 'doing' should surely include investigative activity. This paper addresses the pedagogical question that follows from that philosophical position by attempting to understand how teachers might think about and practice investigative science in the classroom, with particular reference to university-based initial teacher education. It seeks to develop an initial conceptual basis on which beginning teachers may be introduced to investigative science teaching in a way that accommodates the teacher voice that is often absent (Goodson, 1992 ) and acknowledges that theories of action should be grounded in empirical evidence from naturally occurring activities (e.g. Hennessy 1993).

Drawing mainly on preliminary theorising from the shared reflections of twenty secondary science teachers, including beginners, the study is in a Scottish context but related to the wider concern in the literature internationally with the nature of science in teacher education (e.g. Veal 2004; Abd-El-Khalick 2005; Hipkins, Barker and Bolstad 2005). The lack of pedagogical and philosophical clarity identified by Laws (1996) is 
still an issue in the literature. In this paper, the term investigative' is used in preference to other terms with a similar connotation, for example 'exploratory', 'experimental', 'discovery' 'problem solving', 'open-ended' and 'inquiry'. This is partly because the secondary science curriculum documents in Scotland use 'investigations' as their chosen terminology, partly because it is a broad enough term to include or approximate to the other terms and yet also convey, in a science-teaching context, a more authentic picture of the practical nature of scientific activity. A degree of 'openendedness should indeed be presumed as it the use here of 'investigative' is intended to intended to convey some uncertainty of outcome (on the pupil's if not the teacher's part), less associated with more routine practical work such as measurement, specific techniques or standard experiments in a prescribed curriculum.

\section{Specific illustration from the Scottish context}

The practical investigation became an official part of the science curriculum for all children in Scotland in the early 1990s with the introduction of Standard Grade, the two-year course before the end of the compulsory period of education at sixteen years old. Until then there was highly uneven experience across the country: some exploratory work in some primary schools, little or nothing in others; no official requirement in secondary schools at all except for advanced specialist study in 'preparation' for higher education (despite its widespread absence from degree courses in science!). It was an assessment-led innovation in which the investigation conducted was graded on performance of discrete experimental skills (e.g. identify investigable aspects of a problem, articulate a working hypothesis, control relevant variables). The method of assessment was founded on work done on developing techniques for assessing practical skills by Bryce et al (1991).

In a contemporary curriculum paper in the same national context (Learning and Teaching Scotland 2004), it is claimed that 'an open investigation is more likely to motivate pupils by challenging their thinking and allowing them to investigate aspects of science that they are interested in' (p.30); and that 'open-ended investigations that encourage pupils to work scientifically, raising their own questions that they can test or investigate' should be one purpose of practical work for pupils (p33). The difficulty for teachers lies in two areas. Firstly, the experience is separated into component skills or 'skill strands'. In this case, three are identified - 'preparing for tasks, carrying out tasks, reviewing and reporting on tasks' - with the claim that 'the most cognitively challenging skill (for pupils) is preparing, since it involves what, how, resources, sequence, data, safety'. No basis for this debatable claim is given. Secondly, curriculum documents and texts tend to give formulaic illustrations for teachers that fail to inspire or capture the creative nature of the experience suggested in their rhetoric.

Again, in this case, three exemplars are given which 'provide ample (my emphasis) opportunity for the development of investigative skills'. The essence of one of these is to 'demonstrate' the effect of pollution on a pond in which the pupil has to 'decorate a spoon like a fish' and put it in a jar of water; the conclusion (which is given to the 'investigation') is that that 'the more pollution added, the more the habitat is destroyed' (p33-35)! It must be highly doubtful whether trivial examples of this kind are capable of translating respectable rhetoric into related and worthwhile open-ended activity in the science classroom. Much of the practical guidance for teachers is written in a prescriptive form, as if there are investigations that work if a certain series of steps 
are followed. The basis for such advice is neither connected to the aspirational rhetoric nor grounded in the experience-based discourse of practising teachers.

\section{The practice and tacit knowledge of experienced teachers}

The problem with theory in initial teacher education, of course, is that students tend to see it as remote and of little immediate relevance to them. Practice, on the other hand, however appealing, tends to exist as tacit knowledge within individual teachers. Built on experience, it is not a simple matter to impart personally gained wisdom to those who have no such experience. In the area of investigative science, there is the further complication that practitioners' experience and advice is tempered by the requirements of official assessment procedures. A representation of the practitioner perspective that might inform the thinking of beginners is now given. It is based on a symposium on investigative science teaching at which 20 local science teachers of varied experience (students to 25 years of teaching) participated in presenting and discussing their experiences and reflections. The method of data gathering and analysis was adapted from previous research (McNally et al. 1997) where group interviews were used to generate initial insights, somewhat similar to a focus group approach (e.g. Crabtree et al. 1993). All presentations and discussions were recorded and transcribed and served as the raw data on which the following analysis is based. The interpretation derives from sustained interaction during the process of coding and categorizing (Glaser 1978), inevitably influenced to an extent by personal experience as a teacher and teacher educator.

Teachers' views on the formally assessed investigation

For some teachers, the formal investigations meant a 'loss of valuable time for theory', exacerbated by doubts that they actually added anything to pupil understanding or enjoyment of science. The 'waste of time' also lay in the bureaucratic demands on staff of organising and marking. These official investigations were prescribed from a given bank of recipes and routines, typically of an undemanding nature which ultimately trivialised the activity some girls were deciding do they get more bubbles when you put in more detergent or not... I mean that's one of the (Examination) Board's recommended things Examined investigations had become 'so stupid and out of context that they're really just meaningless'. They were a false experience of science where pupils followed a procedure and wrote what the teacher said into their booklet to obtain a higher grade. The combined effect of triviality, being out-of-context and emphasis on procedure seemed to negate the spirit of investigative work; it altered the whole character of the investigative experience to the extent that the investigation was not actually investigative in nature:

I think the problem comes with the formally assessed investigations, in which pupils simply lose any natural curiosity. They really just want to be told what to do to get the grades... what they're (the examiners) saying is that only if you assess these skills will they be developed, and I would say that I would completely disagree with that. I think it's the opposite in fact. When you impose assessment the whole thing changes. There is a problem if you assess practicals. The pupils won't do it for any intrinsic reason. They do it purely because they want a good grade.

Focus on the so-called separate skills was seen to act against their very development. The perception of many was that pupils missed out on any sense of the investigation as a whole experience; they 'lose any natural curiosity' and, therefore, may actually regress 
as investigators. The formally assessed practical investigation was not only noninvestigative; it had become anti-investigative.

On the other hand, some took the view that the formal investigation could be turned into something worthwhile for pupils. The assessment requirement provided a degree of pupil entitlement in that investigative experience was not now dependent on the whims of individual teachers or science departments. The examined investigation need not result in compliance with an imposition but could be turned into a unique experience for pupils that filled a curriculum gap:

I think the investigations give a unique experience that they don't get from doing class experiments... I accept that there are problems with them and there are times when I can see them far enough but I think that we should be looking more positively at seeing if there's a fault there where we can improve on it rather than just getting rid of it. I think there will be a big gap in pupils' knowledge and skills if we get rid of them and don't replace them with some sort of alternative

These teachers saw a more formative, developmental purpose for learners in the formal investigation. Through doing investigations and receiving feedback, pupils do learn, do become better at investigating and 'the majority see it as their own piece of individual work and get quite protective over it'.

\section{Holistic and skill-based investigations}

Teachers' accounts indicated that they thought of investigating as a holistic kind of experience rather than the segmented activities that constituted the investigative process for assessment purposes. In trying to secure entitlement for all, policy makers have no doubt relied on formal assessment but their emphasis on criteria for component skills appears to conceptually mis-represent a process of which we are only beginning to gain a pedagogical understanding. Gott and Duggan (2002) also identify the unfortunate outcome of formal assessment: the obsessive quest for reliability and consequent focus on the readily measurable has neglected the need for validity and what counts as worthwhile scientific activity in the classroom, thus inhibiting open-ended science, complete practical investigations and creative problem solving in science.

The main reason for conducting investigations is ostensibly to give pupils an insight into the practice of science, surely a noble aim, but, as Donnelly (1995) argues, there is a large body of literature which reveals that science is a 'complex, differentiated and subtle activity, often involving conflicting points of view'. Such activity does not appear to be readily nurtured or accommodated by formally assessed investigations. The practice of discrete skills has its place of course, but pupils also need the whole investigative experience in which skills of observing, considering evidence, drawing conclusions etc. can naturally develop as they 'do' science alongside teachers as scientists. The reservations and objections of teachers find support and expression, moreover, in the analysis by Hodson (1992), who argues that doing science is an untidy, unpredictable, idiosyncratic activity that depends crucially on tacit knowledge. He actually condemns skills-based assessment of investigative practical work as philosophically unsound (because it is not science), educationally worthless (because it trivialises learning) and pedagogically dangerous (because it encourages bad teaching). and argues that the policy need for summative assessment may be better served by the use of holistic judgement by teachers as connoisseurs. As with scientists, it is the generation of the idea and its pursuit, the entirety of the investigation, which matters most, but which also provides the context for skill development. It is surely that whole 
experience which is important for pupils and is worthy of pursuit, not the vain quest for reliability and grading.

\section{Different kinds of classroom practice}

Nevertheless, the transcript data show that some science teachers have begun to integrate investigative science into their teaching, despite their doubts about the value of the examined investigation. Some had clearly 'tinkered' with investigative-type work for many years; others had been stimulated by formal assessment requirements to incorporate the idea into their teaching as an important, different kind of activity. Scrutiny of teachers' descriptions in the transcript suggests that there were three fairly distinct ways in which they did this. There was, firstly, investigative work as an 'add on' to the normal curriculum, extra, separate whole class (inclusive) activities that could offer pupils the opportunity to come up with their own questions but still allow the teacher time to consider support. Another approach was to 'add in' investigative work by ( $p$ )rewriting existing practical activities in an investigative manner as (an integrated) part of the normal work of the class, also inclusive but teacher-given rather than pupil-initiated. Thirdly, there was the ad hoc pupil-initiated investigation, a question arising from conventional practical work or even 'out of nowhere', but supported by the teacher as and when it happened.

This latter is not an abstract, idealised picture, for it appears to happen in some teachers' classrooms. In such spontaneous situations, pupils may be closer to a more authentic form of how science is practised by scientists. The image of questions springing from the minds of children during 'normal' classroom science, with a teacher confident of her capacity to support them, evokes the 'loose opportunism' mentioned by Einstein in a letter to a colleague as his preferred method (Feyerabend, 1993). Though he could not bring himself to accept uncertainty in theory of the physical world, Einstein seemed to recognise it in himself as a learner and investigator in the form of 'loose opportunism'. Perhaps we should consider adopting his expression to convey that sophisticated teaching state of mind, that grounded sense of professional ad hoc-ery which seems to epitomise the imaginative pedagogy of authentic science.

\section{Components of confidence for teaching investigative science}

The insights into teacher thinking above are largely derived from their need to engage with assessment-driven policy. A further insight gained is that they tended to talk about what gives them 'confidence' to engage in investigative work with classes. This pedagogical confidence appears to have certain identifiable components to which they variously refer. They made no explicit reference to what they felt they had had to know; teachers did not talk in terms of the types of knowledge they needed to possess. Their accounts suggest a kind of action-related thinking, typical of the nature of professional knowledge (Schon 1983), which perhaps explains the absence of conscious categorisations of activity in their classrooms, even when they tacitly know what is taking place. Indeed the ascription of tacit knowledge (e.g. Eraut 2000) reflects more of their feeling of confidence in their ability to make things happen in the classroom than any espoused categorisation of their knowledge. Others too (e.g. Bryce and Gray 2004; Jarvis and Pell 2004) refer to developing teachers' pedagogical confidence, so the position taken here is that it is more as components of confidence that certain kinds of tacit knowledge underlie teachers' capacity to take advantage of investigative opportunities that may arise in their classrooms. In epistemological parlance, however, 
the developing tacit knowledge base for the confident pedagogy presented here is closely related to the concept of pedagogical content knowledge (Shulman 1986), increasingly cited in recent literature (e.g. Abd-El-Khalick 2005). It is as broad components of confidence rather than identifiable elements of knowledge, however, that the thinking of this sample of teachers is conceptualised here, and given below (with no significance attached to the order). These components also reflect a certain holistic nuance within teacher discourse. This holistic rather than atomistic reporting by practitioners has been observed in workplace learning generally by Prawat (1998).

\section{Teachers' views of pupils and their learning}

What appears to matter to teachers is that, one way or another, pupils become engaged in investigative activity. The expectation that all pupils were capable of such engagement was occasionally explicit as in 'anyone can do an investigation'. Woolnough (1991) suggests that starting with a teacher-given investigation somehow prepares the ground for pupils to then initiate their own. The more realistic picture here is of teachers having a sense of pupils' prior curriculum knowledge and aptitude. Indeed, the idea that an investigation needs a base of prior subject knowledge on the part of pupils was expressed frequently in the discourse. This is a fairly strong, grounded echo of Hodson and Bencze's (1998) action research that student-driven scientific inquiry tends to arise from theory, and also the claim by Roth (1996) that such pupil knowledge tends to be meaningfully applied in investigative situations.

Teachers spoke about how children 'enjoyed' investigations, not about what they 'learned' in a cognitive sense. There was a vague sense that they gained something from the experience - 'they went through a sort of improvement', 'eventually they took it a stage further' - that they became better at investigating through investigating. We might attribute teachers with an implicit awareness of the concept of ability as a form of developing expertise (Sternberg 1998) but the absence of claims about what children learn from investigating does support a cautious view about the benefits of tightly defined curriculum objectives, (e.g. Cleminson 1990; Driver and Bell 1986). There was no indication that teachers saw investigative work as superior to other tasks and activities; it was simply and essentially a different kind of experience. There is clearly a discrepancy between the language of teachers and the language of policy hereperhaps even a conflict of concepts - that demands further exploration of what (teachers think) children learn experientially from investigating. Indeed, teachers' notions of the activities themselves were that they were vaguely investigative, certainly not scientifically sophisticated, but yet important for pupils in some kind of introductory way, rather like Laws' (1996) notion of preliminary investigations that pupils may need to better define a problem.

\section{Teacher biography and attitude}

The role of teachers in investigative work is clearly much wider than generating ideas, devising questions or even being receptive to pupil suggestions. Teachers' discourse certainly revealed a spectrum of teacher attitude towards investigative activity, which related mainly to beliefs about its importance and feasibility. Length of teaching experience mattered here but again in a rather polarised way. For some, this had hardened their attitude against it - classroom bedlam, inadequate resources, pupil apathy and ignorance were typical reasons - but for others it meant they were able to 'take a chance'. The security of an established reputation in a school involved less risk to credibility with colleagues and maintenance of classroom order though pupil 
behaviour, so to speak, was ambiguously construed as a reason for doing or for not doing investigative work. Jarvis and Pell (2004) found that primary teachers became more positive about classroom science once they appreciated that potentially disruptive children could be managed during practical investigations. Experience, of course, meant greater familiarity with the whole science curriculum, resource provision and class management and, therefore, an ability to control some of the more tangible aspects of support.

Another point was the teacher's actual experience of doing scientific investigation - or more commonly the lack of it. Supporting investigative work by pupils without having had the actual experience oneself was a cause for anxiety; there was often nothing to draw on. With little or no experience of doing science themselves, or even having contact with working scientists, many teachers' working knowledge of science is somewhat hollow. Hodson and Bencze (1998) found that this did affect teachers' confidence in their own ability to support investigations by pupils. Two teachers in this sample had experience of routine laboratory work as scientists before coming into teaching but they felt this was of limited use in supporting investigative work. For most teachers, their model of scientific practice is based solely on their time in school and higher education. Even well-intentioned curriculum documents may be an inadequate substitute for real working experience. In relation to pupil achievement, Alters (1997), for example, reports that in the USA there has been no impact, despite half a century of emphasis on the nature of science in teacher training. On the other hand, in a close case study of a teacher's interaction with pupils in an open-inquiry engineering curriculum, Roth (1996) largely attributes her remarkable success to her 'experience as...observer of many construction sites and interaction with engineers'.

Teachers of science obtain most of their understanding of the nature of science, as Nott and Wellington (1996) argue, from their classroom experiences and academic histories, which may well not be adequate as a preparation for an authentic investigative pedagogy. However, a simple conviction of its importance may clearly be enough motivation for some teachers: 'there's nothing better than finding something out for yourself, so it could only be a good experience for them, even if it doesn't work'. Given the absence of a background as a working scientist it may be that those teachers who successfully nurture investigative activity have come to do so through experiential learning in their own classrooms or, perhaps even more widely, as a consequence of their own particular biography. In making a more general case, Alheit and Dausien (1999) use the term 'biographicity' for the capacity or potential that people have that cannot be taught by experts. Thus, some (even new) teachers are somehow able to begin to teach investigatively before their knowledge base or confidence would suggest that they are ready. In a similar vein, Hodkinson and Hodkinson (2004) argue that it is individual dispositions, which make some teachers more inclined to perceive and act on opportunities within their classrooms.

\section{Resources in a wider classroom context}

Teachers who supported investigative work did show flexibility in their view of resources, an attribute close to what Donnelly (1998) described as a loosening engagement with the laboratory. One, for example, imported ideas and resources from the real world for some relevant 'fiddling around'; another extended the science investigation beyond conventional practical work to a more exploratory, multi-resource activity that could spill outside the classroom. Both examples also illustrate a sense of 
seeking more authentic contexts for investigating (Roth and Roychoudhury 1993). They also illustrate the frequent allusion by teachers to resource availability, access and organisation in supporting investigative activity. This is recognised as a factor in the learning environment by Holstein, Cohen and Lazarowicz (1996), and is likely to be particularly critical in supporting activity of an investigative nature.

\section{The experience of beginners}

It is proposed then that access to these aspects of teacher thinking is an important input to student teachers' learning - both teachers' views on formal assessment and the more latent conceptual base of their thinking. However, the experience of the beginners in the sample has a particular, perhaps closer relevance to the development of an ITE curriculum. Current practice in the author's institution is that student teachers of science are required to attempt a small-scale investigation with a small group of about eight 12-13 year-old pupils in their microteaching/link practice course (in which they practise teaching small groups of pupils for some 20 minutes once a week over two eight week stretches) prior to their first 5-week teaching placement in a secondary school. This is a protected environment with the intention of simply introducing students to the experience of investigative teaching. It is a first, small, low risk step. It is not formally evaluated although it is discussed informally in seminars. This communal reflection on the experience is considered to be valuable in itself. A specific example arose at the symposium:

I've already had a bash at one in link practice at university. It was quite well structured, you know, because it was first year kids and we thought we'd do an investigation on the sixth sense - a bit ambitious maybe but they worked at it well and they were all very interested in it ... the problem I found was trying to get them to make some conclusion from what they had written

Apart from meeting the modest aim of having this initial pedagogic experience outwith the prescribed curriculum, the interesting irony is that the student refers to the making of a conclusion, as a particular difficulty for the pupils (recall that mention of component 'skills' was noticeably absent from the discussion of experienced teachers). Although the investigation as a holistic, rather than atomistic, experience is grounded in the accounts of the experienced teachers in the sample, it may be that the opportunity for protected experience and reflective discussion in the ITE environment can create an early sensitivity to a rather different pedagogy. The student quoted above isolated from his limited practice the drawing of a conclusion as a possible learning and teaching difficulty. Certainly, Millar et al (1994) have argued that pupils do need introduction to what constitutes evidence and Duggan, Johnson and Gott (1996) found that appreciating the concept of a variable was absent from the understanding of 12-14 year olds doing investigative work. If teachers are to develop such insights themselves then it appears that this may profitably begin in ITE.

The other references by the three students at the symposium tended to focus on their actual placement experience (a five-week practice several weeks earlier) and brought to the fore some of the anxieties of the experience: 'not knowing where things are ... being in an unfamiliar situation ... knowing less than the pupils about something ... not knowing the curriculum as a whole ... no previous experience of investigating. This is largely to do with the 'not yet known' that becomes embedded in the practice of more experienced teachers, tacit knowledge that they take for granted and is, as argued earlier, implicit 
rather than explicit in their discussion. Yet it could scarcely be more nakedly explicit in the discourse of students:

I've never done an investigation by myself so I think it's more daunting that children are learning to think that way... I mean the wee boy asked me about humidity and I almost fell off my chair, but I'm just so nervous and about half way through when I thought it was working, I just thought thank you. I don't know what I did but it worked anyway, and I just said to that wee boy "right on you go, just go and find your plastic bags and do what you want", and his was the best result... so I was dead chuffed. I suppose it's good not letting your panic show through sometimes

I just don't know if I could do it, but I found so many constraints just doing basic experiments... I do think that investigation is a part of science, that is what science is like... but it is really hard because you've got to think "can I cope with that situation yet?" and I don 't think I could. Maybe I could with a smaller one like when you said there was a little boy who said "oh would humidity affect it?", and you let him go and try it out and it was fine. If something as simple as that came up then yes, but when you didn't know where the plastic bags were, having to think "well where is everything?"... it's just the fact that you're not in a totally familiar situation, and they (other teachers) do know the curriculum

No ITE course can realistically bring students to a level of knowledge that they would consider adequate for 'confident' investigating. In any case, that knowledge and confidence depend on a degree of familiarity with the particular context-knowledge of pupils and resources, for example. In addition, familiarity with the whole curriculum cannot be realistically achieved in any ITE course; it is acquired through teaching over the years. There will also be areas of science not covered in a degree (e.g. humidity above), which expose the beginner's fragile confidence in her own scientific knowledge. Nor can a brief, protected exposure to investigative pedagogy in ITE (that these students have) compensate for the absence of doing investigative science. What it may do is persuade them that it is 'part of science' and that it may well mean a step into the unknown where you 'let him go and try it out'. Some exposure in ITE may be enough to sow a seed of reasoned belief in taking the step, and that this step - 'it worked anyway ... his was the best result' - though it evades easy post-hoc analysis, will affirm such a leap of faith.

Equally explicit in the student accounts is an emotional dimension to the experience. What they feel is as important as what they know - or do not know. This is expressed through their anxiety before the event - 'it's more daunting ... I almost fell off my chair ... I'm so nervous ... it is really hard ... can I cope?' - but with some relief and pleasure when it appears to work - 'I just thought thank you ... I was dead chuffed (pleased)'. However, the anxiety may well not be assuaged by one successful experience. One former student in her second year of teaching revealed as much emotion as the students and a premonition of what is in store for them once they enter the real world of teaching:

I've only been in the job a year... and you don't want them to ask you any awkward questions. The sweat's running down your back as well, so what I tried last year and it worked okay -section 12, the earth ... I can't get any enthusiasm for it myself - I ended up with these three second year classes which was a nightmare. So what I tried to do was to generate these investigations from them. What I do is plan it first, then I take in all their plans and sort out all the lists of stuff that I need for the next week. I got 
them to write out all their plans, however rubbish they were, and I got them to write a list at the bottom of all the things that they would need. And then for the next week I checked it. Obviously if it was expensive well I couldn't get it, so I just said you'll need to rethink it. But I went and begged the technician to try and sort things out, pinched it from other people, and I managed to get off the ground... You know what they're sort of going to come out with but they're still generally on their own. You're not leading them into it but you are looking at their ideas.

Despite having more situated knowledge and an approach that gave her time to prepare support, there are signs of stress. This is clearly a much larger undertaking by this new teacher, a conscientious attempt to provide an investigative experience for all her pupils. The scale of response to this concerted spontaneity is so overwhelming that she has to delay it. Indeed, given her relative inexperience, she is over-extended and has perhaps been over-ambitious. The combination of uncertainty of outcome and the organisational implications inevitably turn up the heat to the point where the sweat is running down your back'. Brinkman and de Jong (1996) argue that novice teachers need early exposure to teaching investigative science if they are to avoid later loss of confidence, but the leap from controlled exposure in ITE into the reality illustrated here is almost too much to expect from a beginner. Some exposure to the difficulty of teaching investigatively is important but learning how is surely better supported, as Lederman and Latz (1995) argue, through a balance between such exposure and what the new teacher can be expected to deliver in the classroom.

In any case, the experience of beginning teaching in general is strongly defined by its emotional nature. During the first few months or so it is likely that the inevitable preoccupation with survival and belonging are simply too pressing for students to engage in pedagogic experimentation. The risks associated with investigative teaching could render them even more vulnerable in their ineluctable quest for acceptance and credibility as a teacher. Nor is it necessary at this fragile moment of professional learning. Subject knowledge is curiously conspicuous by its absence from new teachers' accounts of their early experience (McNally et al 2004) and may be a 'taken-forgranted' dimension of their early professional learning. Provided the seeds of investigative pedagogy has been sown and nurtured in the formative phase of ITE, there will be an opportunity to expose it to the real environment of the school, once the various components of confidence are felt to be settling into place. The new teacher herself can then choose the class, the topic and the moment.

\section{Concluding Discussion}

So, what should be the nature of intervention in ITE? What can be done to enable beginners to start teaching investigatively? It may be that the ability can be developed from an introductory non-threatening experience in ITE to further safe trials in a teaching environment during the induction period in which the new teacher's undeveloped knowledge and emotional vulnerability are not unduly exposed. For many beginners the transition into the real world of teaching is experienced as a quantum leap into an unknown complex of new relationships with an uncertainty of acceptance.

Nevertheless, teaching science investigatively, even outside the specialist discipline, can help new teachers with discourse and difference amongst pupils (Finlayson et al 1998). Since new teachers do appear to begin to understand difference in a real way during the first few months of teaching (McNally et al 2004), it may be that investigative teaching can be synchronised with their wider development during this early learning phase. 
Of course, there is only so much that can be covered in any course of Initial Teacher Education. As the range of policy-directed content continues to increase, the space for coverage of subject-specific aspects such as the teaching of investigative science is squeezed. Nor is there any explicit recognition of what beginners may or may not be ready to learn. Naturally, student teachers want to be well prepared for the demands of the classroom in their first teaching post. While this expectation is difficult to meet, students tend to accept, in my experience, that a balance has to be struck between the accommodation of immediate needs and the laying down of a foundation of ideas for further development at some later stage. On the basis of the strands of evidence presented in this paper, it is, therefore, suggested that a foundation can be established in an ITE curriculum by combining protected experience of practical investigative teaching with a meta-theory of the components of confidence needed for further pedagogical exploration. This confidence is also dependent on the relational conditions they experience in school, on student placement and in the early months of teaching (McNally et al 1997).

Following the initial phase of vulnerability, the professional learning that takes place may be construed as a continuing cycle of developing confidence and expertise. It is a learning cycle, however, that can and should be set in motion during ITE. Diagrammatic modelling is a temptation at this stage in theory development but too often such attempts are inadequate as they can never be complete pictures of a complex process as dynamic and organic as teaching. Brown and McIntyre's (1993) model, for example, did attempt to make sense of teacher thinking and was partly successful in moving on our understanding of teacher thinking from rigid objectives-based planning to an appreciation of the complex interplay of conditions that govern teachers' decisions about how they act in their classrooms. Although the pedagogical focus of this study is more on the process of teacher learning and development, it does suggest that the teacher's knowledge base is more uncertain, affective and biographical. The substance of any potential model emerging from this theorising would be the identification and connection of components of confidence that offer a cyclical sense of pedagogical development in which ITE intervention is a kind of kick-start, or boost to some buried autobiographical memory. It is a pedagogy of investigative science for beginners, built mainly on some insights into the experiential learning of teachers, an initial grounded theory of how we might sow the seeds of authentic classroom science activity in early professional learning.

Apart from the experience of actually working as a scientist (which is not typical and would be difficult to guarantee), the other area of knowledge that could complete the foundation is study of the nature of science. Broadly speaking, this would cover the philosophy of science and include, for example, the history of scientific ideas and biographies of scientists. Abd-El-Khalick (2005) found that students who followed a course on the philosophy of science developed deeper, more coherent understandings of the nature of science and tended to incorporate this into planning and discourse related to their own teaching. A distinctive benefit of the protected experience of investigative teaching is that it simplifies and reduces the technical and practical barriers and allows student teachers to experience the more emancipatory (Habermas 1971) potential of investigative science on a safe, small scale. 
Given the crowded ITE curriculum, however, and the probability of only the briefest of introductions, a more extended study of the philosophy of science might be effectively positioned one to three years into the teacher's career once a certain level of experience and confidence in investigative science teaching has been achieved. Hipkins, Barker and Bolstad (2005) identify the international research that points to the stubborn persistence of naive views of science held by teachers, relating to the traditional content domination of tertiary science learning, delivered by university teachers who themselves may lack direct experiences of working science. They suggest that beginning teachers who do wish to implement more innovative curricula may be quickly pulled into line by the modelling of their more experienced colleagues. They also report on the paucity internationally of pedagogical approaches to the nature of science and remind us that teachers have to 'integrate multiple demands in the moment in the classroom'. A further impetus for investigative science and these related matters in ITE lies in the recognition that the children educated in science by teachers become the public of the future. The absence of articles on teacher education in the journal dedicated to the public understanding of science (PUS website 2005) suggests that this connection is not adequately recognised.

Research on teacher education recognises but has not yet begun to resolve the interplay of biography, beliefs and types of intervention in science teaching. Veal (2004) identifies this as a significant issue but also argues that prospective teachers could benefit from greater awareness of the practice and knowledge base of more experienced teachers. This paper has begun to identify what that awareness might consist of, though it argues that the knowledge base is tacit and may be better conceived as certain broad components of confidence, and that the practice can take different forms. Illustrations from teacher discourse give at least some indication of the inherent complexity, uncertainty and risk in the pedagogy of investigative science. The need to acknowledge this and conceptualise from such data is consistent with the phenomenological position of Roth and Tobin (2001) that developing our understanding should not be abstracted but revealed in reference to the particular through unfolding contingencies. It is also proposed that it is possible for teachers to achieve a confident pedagogy of loose opportunism that nurtures and responds to the investigative urges of children in the science classroom, and that this can, and should, begin in initial teacher education. 


\section{References}

ABD-EL-KHALICK, F. (2005). Developing deeper understandings of nature of science: the impact of a philosophy of science course on pre-service science teachers' views and instructional planning. International Journal of Science Education, 27, 1, 15-42.

ALHEIT, P. and DAUSIEN, B. (1999). 'Biographicity' as a Basic Resource of Lifelong Learning Paper presented to European Conference on Lifelong Learning, University of Bremen

ALTERS, B.J. (1997). Whose Nature of Science? Journal of Research in Science Teaching 34, 1, 39-55.

BRINKMAN, F. and DE JONG, O. (1996). Science and Mathematics teacher education: some themes of general interest. European Journal of Teacher Education, 19, 2, 103115.

BROWN, S and MCINTYRE, D. (1993). Making sense of teaching Bucks, OUP BRYCE, T. and GRAY, D. (2004). Tough acts to follow: the challenges to science teachers presented by biotechnological progress. International Journal of Science Education, 26, 6, 717-733

BRYCE, T.G.K., MCCALL, J., MACGREGOR, J., WESTON, R.A.J. and ROBERTSON, I.J. (1991). How to Assess Open-ended Practical Investigations in Biology, Chemistry and Physics, Heinemann

CLEMINSON, A. (1990). Establishing an epistemological base for science teaching in the light of contemporary notions of the nature of science and of how children learn science, Journal of Research in Science Teaching, 27, 5, 429-445.

CRABTREE, B. F., YANOSHIK, M. K., MILLER, W. L. and O'CONNOR, P. J. (1993).

Selecting Individual orGroup Interviews. In David L.Morgan(ed.), Successful Focus Groups: Advancing the State of the Art, (London: Sage Publications).

DONNELLY, J. (1995). Curriculum developments in science: the lessons of Sc1. School Science Review, 76, 227, 95-103.

DONNELLY, J. (1998). The place of the laboratory in secondary science teaching. International Journal of Science Education, 20, 5, 585-596.

DRIVER, R. and BELL, B. (1986). Students' thinking and the learning of science: a constructivist view. The School Science Review, 67, 240, 443-456.

DUGGAN, S., JOHNSON, P. and GOTT, R. (1996). A Critical Point in Defining Investigative Work: Defining Variables. Journal of Research in Science Teaching, 33, 5, 461-474.

ERAUT, M. (2000). Non-formal learning, implicit knowledge and tacit knowledge in professional work. In Coffield F. (ed.) The necessity of informal learning ESRC Report (Bristol, Policy Press).

FEYERABEND, P.K. (1993). Against Method, London: Verso.

FINLAYSON, H., LOCK R., SOARES, A. and TEBBUTT, M. (1998). Are we producing teacher technicians or science educators? The consequences of differential demands on trainee science teachers. Educational Review, 50, 1, 45-54.

GLASER, B. (1978). Theoretical Sensitivity (Mill Valley, CA: Sociology Press).

GOODSON, I. F. (1992). Sponsoring the Teacher's Voice: Teachers' Lives and Teacher Development. In Andy Hargreaves and Michael G. Fullan (eds.), Understanding Teacher Development, London, Cassell.

GOTT, R. and DUGGAN, S. (2002). Problems with the Assessment of Performance in Practical Science: which way now? Cambridge Journal of Education, 32, 2, 83-201.

HABERMAS, J. (1971). Knowledge and Human Interests (J.J. Shapiro, trans.) (Boston, MA: Beacon Press) 
HENNESSY, S. (1993). Situated Cognition and Cognitive Apprenticeship: Implications for Classroom Learning, Studies in Science Education, 22, 1-41.

HIPKINS, R., BARKER, M. and BOLSTAD, R. (2005). Teaching the 'nature of science': modest adaptations or radical reconceptions? International Journal of Science Education, 27, 2, 243-254.

HODKINSON, P. and HODKINSON, H. (2004). The Significance of Individuals' Dispositions in Workplace Learning: a case study of two teachers Journal of Education and Work 17, 2, 167-182

HODSON, D. (1992). Assessment of Practical Work: Some Considerations in Philosophy of Science. Science and Education, 1, 115-144.

HODSON, D. (1993). Re-thinking Old Ways: Towards A More Critical Approach to Practical Work. In School Science, Studies in Science Education, 22, 85-142.

HODSON, D. and BENCZE, J. (1998). Becoming critical about practical work: changing views and changing practice through action research. International Journal of Science Education, 20, 6, 683-94.

HOLSTEIN, A., COHEN, I., and LAZAROWITZ, R. (1996). The learning environment of high school chemistry and biology laboratories. Research in Science and Technological Education, 14, 1, 103.

JARVIS, T. and PELL A. (2004). Primary teachers' changing attitudes and cognition during a two-year science in-service programme and their effect on pupils.

International Journal of Science Education, 26, 14, 1787-1811.

LAWS, P.M. (1996). Investigative work in the Science National Curriculum. School Science Review, 77, 17-25.

LEARNING AND TEACHING SCOTLAND (2004). 'Improving Science Education 5-14: Teacher Support.' Glasgow, LT Scotland.

LEDERMAN, N.G. and LATZ, M.S. (1995). Knowledge Structures in the Pre-service Science Teacher: Sources, Development, Interactions, and Relationships to Teaching. Journal of Science Teacher Education, 6, 1, 1-19.

MCNALLY, J., BOREHAM, N., COPE, P. and STRONACH, I. (2004). Enhanced competence-based learning in early professional development. Teaching and Learning Research Programme Phase 3 Project Economic and Social Research Council, London ESRC/ Stirling Institute of Education http://www.ioe.stir.ac.uk/EPL.

MCNALLY, J., COPE, P., INGLIS, W. and STRONACH, I. (1997). The Student Teacher in School: Conditions for Development. Teaching and Teacher Education, 13, 5, 485498.

MCNALLY, J. (2000). Teaching investigative science: preliminary theorising from the shared reflections of Teachers. International Journal of Science Education, 22, 2, 159176.

MILLER, J.D. (1983). Scientific Literacy: A Conceptual and Empirical Review. Daedalus, Spring, 29-48.

MILLAR, R., LUBBEN, F., GOTT, R. and DUGGAN, S. (1994). Investigating in the school laboratory: conceptual and procedural knowledge and their influence on performance.

Research Papers in Education: Policy and Practice, 9, 2, 207-248.

NOTT, M. and WELLINGTON, J. (1996). Probing Teachers Views of the Nature of Science: How Should We Do It and Where Should We Be Looking? In Welford, G., Osborne, J. and Scott P. (eds.), Research in Science Education in Europe, Falmer Press. OGBORN, J., KRESS, G., MARTINS, I. and MCGILLICUDDY, K. (1996). Explaining Science in the Classroom, Bucks., Open University Press. 
PEKAREK, R., KROCKOVER, G.H. and SHEPARDSON, D. P. (1996). The ResearchPractice gap in Science Education, Journal of Research in Science Teaching, 33, 2, 111113.

PRAWAT, R.S. (1998). Current self-regulation views of learning and motivation viewed through a Deweyan lens: the problems with dualism, American Educational Research Journal, 35, 2, 199-224

PUBLIC UNDERSTANDING OF SCIENCE (2005). http://pus.sagepub.com. REISS, M.J. (1993). Science Education for a Pluralist Society, Bucks., Open University Press.

ROTH, W.M. and TOBIN, K. (2001). Learning to teach science as practice. Teaching and Teacher Education, 17, 741-762.

ROTH, W. M. (1996). Teacher Questioning in an Open-Inquiry Learning Environment: Interactions of Context, Content and Student Responses. Journal of Research in Science Teaching, 33(7), 709-736.

ROTH, W. M. and ROYCHOUDHURY, A. (1993). The Development of Science Process Skills in Authentic Contexts. Journal of Research in Science Teaching, 30, 2, 127-152. SCHON, D.A. (1983). The Reflective Practitioner: How Professionals Think in Action. Temple Smith, London. SCOTTISH EDUCATION DEPARTMENT (1982). Practical Investigations in Foundation Science Edinburgh, National Training Videotape._Edinburgh, SED (now SEED) SCOTTISH QUALIFICATIONS AUTHORITY (1997). Standard Grade Arrangements in Physics, Edinburgh, SQA.

SHAPIRO, B.L. (1996). A Case Study of Change in Elementary Student Teacher Thinking during an Independent Investigation in Science: Learning about the 'Face of Science That Does Not Yet Know'. Science Education, 80, 5, 535-560.

SHULMAN, L.S. (1986). Those who understand: knowledge growth in teaching. Educational Researcher, 15, 2, 4-14.

VEAL, W. (2004). Beliefs and knowledge in chemistry teacher development. International Journal of Science Education, 26, 3, 329 - 351.

STERNBERG, R. J. (1998). Educational Researcher. Abilities are forms of developing expertise, 27, 3, 11-21.

WOOLNOUGH, B.E. (ed.) (1991). Practical Science, Bucks., Open University Press. 